\title{
Associations between measurements of central blood pressure and target organ damage in high-risk patients
}

Ki-Hyun Jeon ${ }^{1} \mathbb{D}$, Hack-Lyoung Kim² ${ }^{2^{*}}$, Woo-Hyun Lim² ${ }^{2}$, Jae-Bin Seo ${ }^{2}$, Sang-Hyun Kim² $\mathbb{D}$, Joo-Hee Zo ${ }^{2} \mathbb{D}$ and Myung-A Kim²

\begin{abstract}
Background: It is not well-known which components of central blood pressure (CBP) are more influential to target organ damage (TOD). This study aimed to determine the relationship between CBP measurements and various types of TOD in high-risk patients.

Methods: A total of 148 patients who had documented atherosclerotic cardiovascular disease or its multiple risk factors were prospectively enrolled. CBP was measured by using applanation tonometry of the radial artery. The following nine TOD parameters were evaluated: left ventricular mass index, relative wall thickness, septal e' velocity, septal E/e', brachial-ankle pulse wave velocity, ankle-brachial index, estimated glomerular filtration rate, urine protein and obstructive coronary artery disease.

Results: The mean age of the study population was $67.1 \pm 9.0$ years and $108(73 \%)$ were male. Among four CBP measurements (systolic, diastolic, mean, and pulse pressures), central pulse pressure (CPP) was associated with the largest number of TOD parameters. As CPP increased, the number of TOD increased $(P=0.010)$, but this association was not observed in other CBP measurements ( $P>0.05$ for each).

Conclusions: CPP had a stronger correlation with TOD than other CBP measurements. Non-invasive CPP could be a useful indicator for predicting TOD in patients at high coronary risk.
\end{abstract}

Keywords: Aortic blood pressure, Arterial pressure, Atherosclerosis, Hypertension, Pulse pressure

\section{Background}

Hypertension is one of the major risk factors for cardiovascular disease (CVD) and is a leading global burden [1, 2]. Because of ease of measurement in a practice setting, brachial blood pressure (BrBP) has been accepted as a gold standard and has been most widely used in the diagnosis, risk stratification and treatment monitoring of hypertensive patients $[3,4]$. Robust evidence also suggests that baseline higher $\mathrm{BrBP}$ is strongly associated

\footnotetext{
* Correspondence: kh12876@gmail.com

${ }^{2}$ Division of Cardiology, Department of Internal Medicine, SMG-SNU Boramae Medical Center, Seoul, Republic of Korea

Full list of author information is available at the end of the article
}

with future CVD outcomes [2]. Recently, the importance of central blood pressure (CBP) in the management of hypertension has been emphasized. It has been suggested that CBP is a more reliable indicator of target organ damage (TOD) and CVD risk than BrBP [5-10]. The vital organs, including the heart, brain and kidney, are more closely exposed to CBP rather than to BrBP [11-13]. Also, as blood pressure (BP) varies throughout the arterial tree, $\mathrm{BrBP}$ is a poor surrogate for $\mathrm{CBP}$ which is lower than the corresponding BrBP [14-16]. The most reliable method to measure $\mathrm{CBP}$ is cardiac catheterization, which can directly measure the pressure of the aortic root using a pressure-sensing catheter [17];

(C) The Author(s). 2021 Open Access This article is licensed under a Creative Commons Attribution 4.0 International License, which permits use, sharing, adaptation, distribution and reproduction in any medium or format, as long as you give appropriate credit to the original author(s) and the source, provide a link to the Creative Commons licence, and indicate if changes were made. The images or other third party material in this article are included in the article's Creative Commons licence, unless indicated otherwise in a credit line to the material. If material is not included in the article's Creative Commons licence and your intended use is not permitted by statutory regulation or exceeds the permitted use, you will need to obtain permission directly from the copyright holder. To view a copy of this licence, visit http://creativecommons.org/licenses/by/4.0/ The Creative Commons Public Domain Dedication waiver (http://creativecommons.org/publicdomain/zero/1.0/) applies to the data made available in this article, unless otherwise stated in a credit line to the data. 
however, it is invasive and costly for using in routine practice. Therefore, several methods of assessing CBP using non-invasive tools have been developed, and its reliability and usefulness have been verified in several studies $[15,18]$.

TOD is earlier structural and functional changes in vital organs in response to long-standing high BP, such as left ventricular hypertrophy (LVH), arterial stiffening, renal impairment, and retinopathy [3]. The presence of TOD is a marker of increased CVD risk $[19,20]$. Thus, evaluation of TOD is important for cardiovascular risk assessment in both subjects with and without hypertension [21]. There have been many studies on the association between CBP and TOD [11, 12, 22-26]. However, most studies focused on 1 or 2 TOD parameters, and data from systemic evaluation of the influence of CBP on various types of TOD in the same subjects have been scarce. In addition, little has been known about which measurements of CBP have a greater impact on TOD. Moreover, the role of CBP has not been well investigated in patients at high-risk. It has been suggested that TOD information is beneficial for risk stratification to determine proper treatment strategies in high-risk patients [27]. Thus, the present study was designed to investigate the relationship between CBP and TOD, using four measurements of CBP and 9 TOD parameters in patients with documented CVD or multiple risk factors.

\section{Methods}

\section{Study design and population}

We prospectively enrolled the study patients aged between 20 and 85 years who had documented atherosclerotic cardiovascular disease (ASCVD), including coronary artery disease and ischemic stroke, or at least two of the traditional risk factors for ASCVD (hypertension, diabetes mellitus, smoking, and obesity) from March 2017 to July 2018. In order standardize the effects of other factors influencing the CBP as much as possible and to perform a more accurate analysis, patients with following conditions were excluded: (1) recently deteriorated chest pain, dyspnea or palpitation; (2) unstable or uncontrolled BP;; (3) left ventricular ejection fraction < $50 \%$; (4) valvular regurgitation or stenosis of moderate degree or greater; (5) the presence of pericardial effusion; and (6) atrial fibrillation or other uncontrolled arrhythmia. The study protocol was approved by the Institutional Review Board (IRB) of Boramae Medical Center (Seoul, Korea) (IRB No: 26-2017-55) and written informed consent was obtained from each study patient.

\section{Data collection}

Body mass index was calculated as weight in kilograms divided by the square of height in meters $\left(\mathrm{kg} / \mathrm{m}^{2}\right)$. Coronary artery disease (CAD) was defined according to (1) a history of myocardial infarction or coronary revascularization, including percutaneous coronary intervention or coronary artery bypass surgery; (2) documented luminal narrowing of epicardial coronary artery more than $50 \%$ on invasive coronary angiography or coronary computed tomographic angiography; or (3) documentation of myocardial ischemia on exercise treadmill test or single-photon emission computed tomography. Ischemic stroke was defined as a previous diagnosis: a history of focal neurological deficit that continued for $>24 \mathrm{~h}$, which was confirmed by brain imaging. Hypertension was defined as previous diagnosis, the use of antihypertensive medications or a resting BP of $\geq 140 / 90 \mathrm{mmHg}$. Diabetes mellitus was defined as a previous diagnosis, the use of oral hypoglycemic agents or insulin or fasting blood glucose $\geq 126 \mathrm{mg} / \mathrm{dL}$. Patients were classified as smokers if they had smoked regularly during the previous 12 months. All subjects underwent laboratory tests by sampling venous blood in the morning after overnight fasting. Blood levels of following parameters were measured by an automated enzymatic procedure: white blood cell count, hemoglobin, total cholesterol, lowdensity lipoprotein cholesterol and high-density lipoprotein cholesterol, triglyceride, glucose, glycated hemoglobin, creatinine, C-reactive protein, and $\mathrm{N}$ terminal pro-brain natriuretic peptide (NT-proBNP). Estimated glomerular filtration rate (eGFR) was calculated using 4-component Modification of Diet in Renal Disease (MDRD) study incorporating age, race, sex, and serum creatinine level [28]. Data were also collected on current medications for CVD, including antiplatelet agents (aspirin and clopidogrel), calcium channel blockers, renin-angiotensin system blockers, betablockers and statins.

\section{Measurement of central blood pressure}

Radial artery pressure waveforms and BrBP were recorded simultaneously using a fully automated device (HEM-9000AI; Omron Healthcare, Kyoto, Japan) to calculate late systolic pressure in the radial artery (SBP2) and to estimate central systolic BP (CSBP) [18]. The HEM-9000AI utilizes both oscillometer BP detection via a cuff wrap at the upper arm and tonometric measurement at the radial artery in the wrist. The device measures oscillometric signals for noninvasive $\mathrm{BP}$ measurement and processes the data through its computer and algorithm within the device. $C B P$ was estimated using a regression equation with SBP2 as a major independent variable [29]. Four measurements of CBP analyzed in this study were CSBP, central diastolic BP (CDBP), central mean arterial pressure (CMAP), and central pulse pressure (CPP). 
Target organ damage parameters

The following nine parameters of TOD were assessed: (1) obstructive CAD defined as $>50 \%$ stenosis in the major epicardial coronary arteries on computed tomographic angiography or invasive coronary angiography; (2) LVH defined as left ventricular mass index (LVMI) > $115 \mathrm{~g} / \mathrm{m}^{2}$ for man and $>95 \mathrm{~g} / \mathrm{m}^{2}$ for woman [30]; (3) concentric remodeling of the left ventricle defined as relative wall thickness $(\mathrm{RWT})>0.42$ [30]; (4) diastolic dysfunction defined as septal $\mathrm{e}^{\prime}<7 \mathrm{~cm} / \mathrm{Sec}$. [31]; (5) diastolic dysfunction defined as septal E/e' >15 [31]; (6) chronic kidney disease defined as eGFR less than $60 \mathrm{~mL} /$ $\min / 1.73 \mathrm{~m}^{2}$; (7) proteinuria defined as albumincreatinine ratio (ACR) $>30 \mathrm{mg} / \mathrm{g}$ in spot urine; (8) increased arterial stiffness defined as brachial-ankle pulse wave velocity (baPWV) $>1,600 \mathrm{~cm} /$ Secs. [32, 33]; and (9) peripheral artery disease defined as ankle-brachial index $(\mathrm{ABI})<0.9$. The tests for TOD, including blood test, urinalysis, ABI, baPWV and echocardiography were performed at the same day of CBP measurement. Computed tomographic angiography or invasive coronary angiography for the CAD evaluation was performed within 1 week of CBP measurement.

\section{Statistical analysis}

Continuous variables are presented as means \pm standard deviation, and categorical variables are presented as number (\%). Pearson correlation analysis was performed to investigate the linear association between the two parameters of CBP measurements and TOD parameters. Scatter plots were used for the demonstration of linear correlations between the two parameters. Mean values of CBP measurements between patients with or without TOD were compared using Student t-tests. Analysis of variance was used to assess the association between mean values of CBP measurements and numbers of TOD parameters. Two-sided P-values $<0.05$ were considered statistically significant for all tests. All statistical analyses were performed using IMB SPSS ver. 20.0 (IBM Corp., Armonk, NY, USA).

\section{Results}

A total of 148 patients were enrolled and analyzed. The clinical characteristics of the study patients are shown in Table 1 . Mean age was $67.1 \pm 9.0$ years, and 108 patients (73.0\%) were male. Ninety-eight patients (66.2\%) and 15 patients $(10.1 \%)$ had a history of CAD and ischemic stroke, respectively. The prevalence rates of hypertension, diabetes mellitus and current smoking in the study population were $74.3 \%, 41.9 \%$, and $25.1 \%$, respectively. The results of most blood tests were within the normal range except mildly elevated blood level of NT-proBNP. Most patients were taking cardioprotective medications, such as antiplatelets (88.5\%), beta-blockers (71.3\%),
Table 1 Baseline characteristics of study population $(n=148)$

\begin{tabular}{|c|c|}
\hline Characteristic & Value \\
\hline \multicolumn{2}{|l|}{ Demographic finding } \\
\hline Age (yr) & $67.1 \pm 9.0$ \\
\hline Male sex & $108(73.0)$ \\
\hline Body mass index $\left(\mathrm{kg} / \mathrm{m}^{2}\right)$ & $25.9 \pm 3.5$ \\
\hline \multicolumn{2}{|l|}{ Comorbidity } \\
\hline Coronary artery disease & $98(66.2)$ \\
\hline Ischemic stroke & $15(10.1)$ \\
\hline Hypertension & $110(74.3)$ \\
\hline Diabetes mellitus & $62(41.9)$ \\
\hline Current smoking & $38(25.1)$ \\
\hline \multicolumn{2}{|l|}{ Laboratory finding } \\
\hline 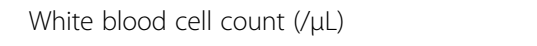 & $7,290 \pm 5,240$ \\
\hline Hemoglobin (g/dL) & $14.0 \pm 1.5$ \\
\hline Cholesterol (mg/dL) & $150 \pm 30$ \\
\hline Low-density lipoprotein cholesterol (mg/dL) & $78.3 \pm 24.1$ \\
\hline High-density lipoprotein cholesterol (mg/dL) & $47.6 \pm 11.7$ \\
\hline Triglyceride (mg/dL) & $135 \pm 83$ \\
\hline Fasting blood glucose (mg/dL) & $119 \pm 33$ \\
\hline Glycated hemoglobin (\%) & $6.35 \pm 1.09$ \\
\hline C-reactive protein (mg/dL) & $0.96 \pm 6.89$ \\
\hline NT-proBNP (pg/mL) & $326 \pm 515$ \\
\hline \multicolumn{2}{|l|}{ Medication } \\
\hline Antiplatelet agent & $131(88.5)$ \\
\hline Calcium channel blocker & $73(48.7)$ \\
\hline Renin-angiotensin system blocker & $121(81.8)$ \\
\hline Beta-blocker & 107 (71.3) \\
\hline Statin & 136 (90.7) \\
\hline
\end{tabular}

Data are presented as mean \pm standard deviation or number (\%) NT-proBNP, N-terminal pro-brain natriuretic peptide

renin-angiotensin system blockers (81.8\%), and statins $(90.7 \%)$. The results of BP profiles and TOD parameters are demonstrated in Table 2. Most patients had obstructive CAD (77.7\%). Table 3 shows the correlations between $\mathrm{BP}$ measurements and 8 TOD parameters. The presence of CAD is a binary variable and is excluded from this correlation analysis. Among eight TOD parameters, CSBP correlated with $\mathrm{E} / \mathrm{e}^{\prime}$ and baPWV, CDBP with eGFR and baPWV, CMAP with baPWV, and CPP with septal e', E/e', eGFR, ACR, baPWV, and ABI. CPP was correlated with more TOD parameters than other CBP and BrBP measurements. LVMI and RWT were not associated with CBP measurement but associated with only brachial diastolic BP. Figure 1 shows the correlations between CPP and each value of TOD parameters. Table 4 showed the mean value of CBP measurements according to the presence of TOD. Obstructive CAD and $\mathrm{LVH}$ were associated with CDBP and 
Table 2 BP profiles and TOD parameters $(n=148)$

\begin{tabular}{ll}
\hline Characteristic & Value \\
\hline BP profile & \\
Right brachial systolic blood pressure $(\mathrm{mmHg})$ & $135 \pm 16$ \\
Right brachial diastolic blood pressure $(\mathrm{mmHg})$ & $77 \pm 10$ \\
Right brachial mean blood pressure $(\mathrm{mmHg})$ & $96 \pm 10$ \\
Right brachial pulse pressure $(\mathrm{mmHg})$ & $58 \pm 14$ \\
Central systolic blood pressure $(\mathrm{mmHg})$ & $139 \pm 19$ \\
Central diastolic blood pressure $(\mathrm{mmHg})$ & $77 \pm 10$ \\
Central mean blood pressure $(\mathrm{mmHg})$ & $98 \pm 11$ \\
Central pulse pressure (mmHg) & $69 \pm 11$ \\
Central augmentation index $(\%)$ & $82 \pm 14$
\end{tabular}

\section{Parameter of TOD}

\begin{tabular}{ll} 
Obstructive coronary artery disease & $115(77.7)$ \\
Left ventricular mass index $\left(\mathrm{g} / \mathrm{m}^{2}\right)$ & $97.2 \pm 26.0$ \\
Relative wall thickness & $0.38 \pm 0.06$ \\
Septal $\mathrm{e}^{\prime}$ velocity $(\mathrm{cm} / \mathrm{sec})$ & $5.9 \pm 1.8$ \\
Septal E/e' & $11.7 \pm 4.4$ \\
Estimated glomerular filtration rate $\left(\mathrm{mL} / \mathrm{min} / 1.73 \mathrm{~m}^{2}\right)$ & $82.0 \pm 22.1$ \\
Microalbumin creatinine ratio $(\mathrm{mg} / \mathrm{g})$ & $127 \pm 444$ \\
Brachial-ankle pulse wave velocity $(\mathrm{cm} / \mathrm{sec})$ & $1,578 \pm 314$ \\
Ankle-brachial index & $1.08 \pm 0.13$ \\
\hline
\end{tabular}

Data are presented as mean \pm standard deviation or number (\%) $\mathrm{BP}$, blood pressure; TOD, target organ damage
CPP. Left ventricular (LV) diastolic dysfunction assessed by septal $\mathrm{e}^{\prime}$ velocity and E/e' were associated with only CPP. LV concentric remodeling and chronic kidney disease (CKD) were not associated with either CBP measurement. Proteinuria was associated with CSBP and CPP. Increased arterial stiffness was associated with CSBP, CMAP, and CPP. Peripheral artery disease was associated with CDBP and CPP. In summary, CPP was associated with the largest number of TOD parameters. Also, CPP value increased as the number of TOD parameters increased $(P=0.010)$. Other $\mathrm{CBP}$ measurements did not show this association $(P>0.05$ for each) (Fig. 2).

\section{Discussion}

Our result, using four $\mathrm{CBP}$ measurements and nine TOD parameters, showed that each CBP measurement were related to different TOD parameters in patients with ASCVD or its multiple risk factors. Among four CBP measurements (CSBP, CDBP, CMAP, and CPP), CPP was the best correlate with TOD. It also revealed that the higher CPP was, the more target organs were damaged.

Vital organs, such as the heart, kidneys, and brain, are more directly exposed to CBP rather than to BrBP. In this study, CPP was correlated with the most indices of TOD (6/8), although both CBP and BrBP parameters could predict TOD well. There is a theoretical background that central aorta is closer to major organs, so CBP's influence is greater than BrBP [34, 35]. CBP represents the true pressure load imposed on the heart,

Table 3 The correlation coefficient ( $r$ ) between BP measurements and TOD parameters

\begin{tabular}{|c|c|c|c|c|c|c|c|c|}
\hline Variable & LVMI & RWT & Septal e' & $E / e^{\prime}$ & eGFR & ACR & baPWV & $\mathrm{ABI}$ \\
\hline$\overline{C S B P}$ & 0.014 & 0.077 & -0.148 & $0.271^{* *}$ & -0.126 & -0.041 & $0.416^{* *}$ & -0.142 \\
\hline CDBP & -0.125 & -0.011 & -0.011 & -0.011 & $0.192^{*}$ & -0.096 & $0.247^{* *}$ & 0.149 \\
\hline CMAP & -0.067 & 0.038 & -0.007 & 0.149 & 0.045 & -0.091 & $0.379^{* *}$ & 0.007 \\
\hline CPP & 0.034 & 0.137 & $-0.236^{* *}$ & $0.306^{* *}$ & $-0.302^{* *}$ & $-0.219^{*}$ & $0.329^{* *}$ & $-0.193^{*}$ \\
\hline BrSBP & -0.011 & 0.065 & -0.096 & $0.267^{* *}$ & -0.090 & 0.032 & $0.398^{* *}$ & -0.151 \\
\hline BrDBP & $-0.233^{* *}$ & $-0.015^{*}$ & 0.131 & -0.015 & 0.139 & -0.096 & $0.218^{*}$ & 0.047 \\
\hline BrMAP & -0.155 & 0.022 & 0.032 & 0.128 & 0.043 & -0.048 & $0.350^{* *}$ & -0.043 \\
\hline BrPP & 0.148 & 0.083 & $-0.197^{*}$ & $0.308^{* *}$ & $-0.196^{*}$ & 0.099 & $0.291^{* *}$ & $-0.203^{*}$ \\
\hline
\end{tabular}

$\mathrm{BP}$, blood pressure; TOD, target organ damage; LVMI, left ventricular mass index; RWT, relative wall thickness; eGFR, estimated glomerular filtration rate; ACR, albumin-creatinine ratio; baPWV, brachial-ankle pulse wave velocity; $\mathrm{ABI}$, ankle-brachial index; CSBP, central systolic blood pressure; CDBP, central diastolic blood pressure; CMAP, central mean arterial pressure; CPP, central pulse pressure; BrSBP, brachial systolic blood pressure; BrDBP, brachial diastolic blood pressure; BrMAP, brachial mean arterial pressure; BrPP, brachial pulse pressure ${ }^{*} P<0.05,{ }^{* *} P<0.001$ 

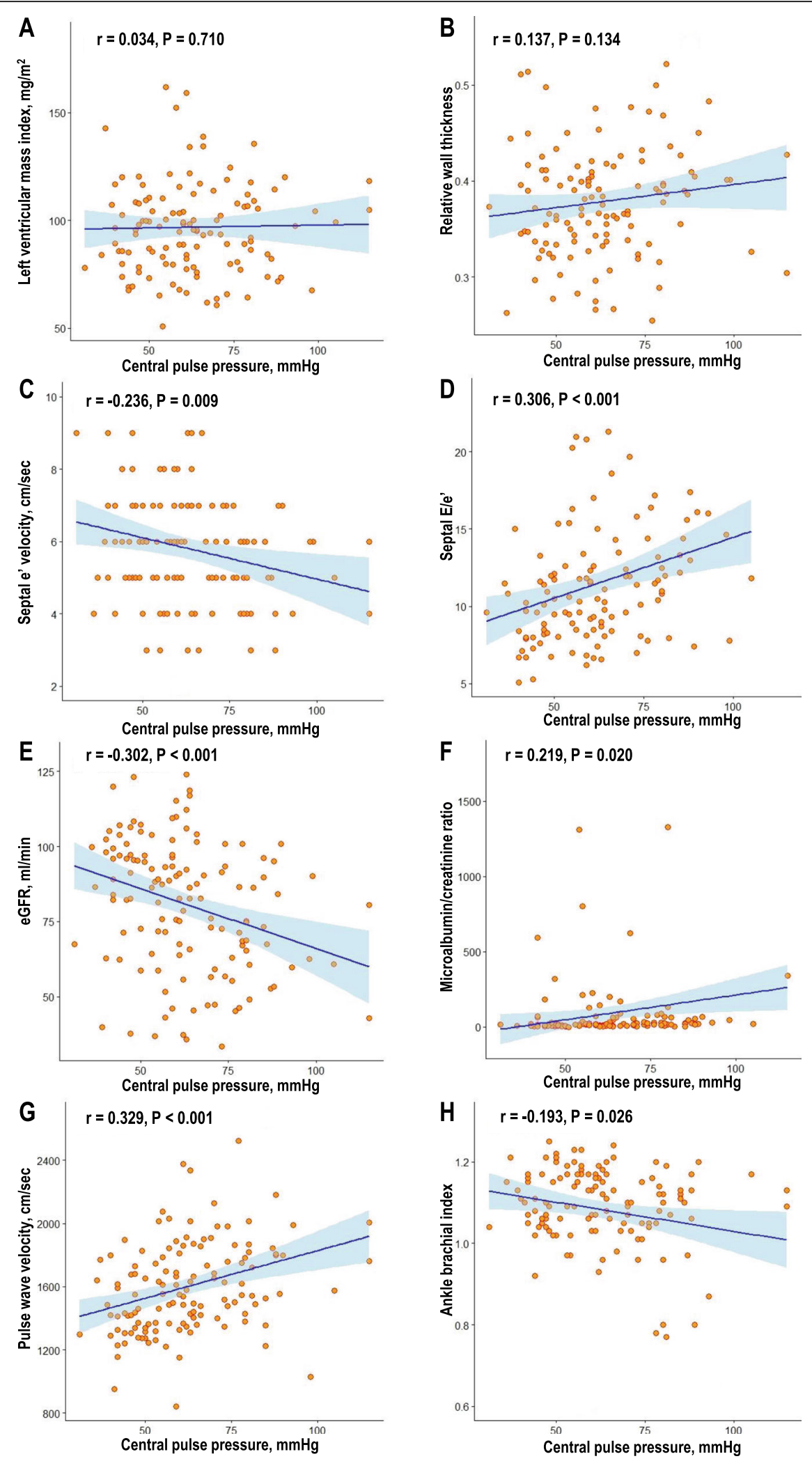

Fig. 1 Correlations between central pulse pressure and various types of target organ damage: A left ventricular mass index, B Relative wall thickness, C Septal e' velocity, D Septal E/e', E eGFR, F microalbumin/creatinine ratio, G Pulse wave velocity, H Ankle brachial index. eGFR; estimated glomerular filtration rate 
Table 4 Mean values of central blood pressure measurements according to the presence of TOD

\begin{tabular}{|c|c|c|c|}
\hline Variable & TOD (+) & TOD (-) & P-value \\
\hline Obstructive CAD & $(+)(n=104)$ & $(-)(n=30)$ & \\
\hline $\mathrm{CSBP}, \mathrm{mmHg}$ & $139 \pm 19$ & $139 \pm 18$ & 0.881 \\
\hline $\mathrm{CDBP}, \mathrm{mmHg}$ & $75.4 \pm 9.7$ & $81.1 \pm 9.7$ & 0.007 \\
\hline CMAP, mmHg & $96.8 \pm 11.3$ & $100.5 \pm 11.3$ & 0.115 \\
\hline $\mathrm{CPP}, \mathrm{mmHg}$ & $64.1 \pm 17.1$ & $56.0 \pm 14.3$ & 0.036 \\
\hline LVMI & $>115 \mathrm{~g} / \mathrm{m}^{2}$ for male and $>95 \mathrm{~g} / \mathrm{m}^{2}$ for female $(n=91)$ & $\leq 115 \mathrm{~g} / \mathrm{m}^{2}$ for male and $\leq 95 \mathrm{~g} / \mathrm{m}^{2}$ for female $(n=31)$ & \\
\hline $\mathrm{CSBP}, \mathrm{mmHg}$ & $140 \pm 20$ & $138 \pm 19$ & 0.770 \\
\hline $\mathrm{CDBP}, \mathrm{mmHg}$ & $72.8 \pm 9.9$ & $77.2 \pm 9.8$ & 0.031 \\
\hline CMAP, mmHg & $95.1 \pm 10.7$ & $97.7 \pm 11.7$ & 0.294 \\
\hline $\mathrm{CPP}, \mathrm{mmHg}$ & $68.1 \pm 20.0$ & $61.3 \pm 15.4$ & 0.041 \\
\hline RWT & $>0.42(n=24)$ & $\leq 0.42(n=98)$ & \\
\hline $\mathrm{CSBP}, \mathrm{mmHg}$ & $142 \pm 23$ & $138 \pm 18$ & 0.311 \\
\hline $\mathrm{CDBP}, \mathrm{mmHg}$ & $76.0 \pm 10.8$ & $76.1 \pm 9.8$ & 0.976 \\
\hline CMAP, mmHg & $98.2 \pm 12.9$ & $96.7 \pm 11.1$ & 0.565 \\
\hline $\mathrm{CPP}, \mathrm{mmHg}$ & $66.7 \pm 21.0$ & $61.9 \pm 15.6$ & 0.307 \\
\hline e' velocity & $<7 \mathrm{~cm} / \mathrm{sec}(n=105)$ & $\geq 7 \mathrm{~cm} / \mathrm{sec}(n=17)$ & \\
\hline $\mathrm{CSBP}, \mathrm{mmHg}$ & $140 \pm 20$ & $132 \pm 14$ & 0.113 \\
\hline $\mathrm{CDBP}, \mathrm{mmHg}$ & $75.6 \pm 10.1$ & $78.9 \pm 8.6$ & 0.216 \\
\hline CMAP, mmHg & $97.1 \pm 11.8$ & $96.7 \pm 9.7$ & 0.888 \\
\hline $\mathrm{CPP}, \mathrm{mmHg}$ & $64.4 \pm 17.1$ & $53.1 \pm 10.6$ & 0.010 \\
\hline$E / e^{\prime}$ & $>15(n=25)$ & $\leq 15(n=97)$ & \\
\hline $\mathrm{CSBP}, \mathrm{mmHg}$ & $143 \pm 23$ & $137 \pm 18$ & 0.173 \\
\hline $\mathrm{CDBP}, \mathrm{mmHg}$ & $73.8 \pm 11.9$ & $76.7 \pm 9.4$ & 0.192 \\
\hline CMAP, mmHg & $97.1 \pm 14.5$ & $97.0 \pm 10.6$ & 0.967 \\
\hline $\mathrm{CPP}, \mathrm{mmHg}$ & $70.1 \pm 16.5$ & $60.0 \pm 16.5$ & 0.015 \\
\hline eGFR & $<60 \mathrm{~mL} / \mathrm{min} / 1.73 \mathrm{~m}^{2}(n=27)$ & $\geq 60 \mathrm{~mL} / \mathrm{min} / 1.73 \mathrm{~m}^{2}(n=107)$ & \\
\hline $\mathrm{CSBP}, \mathrm{mmHg}$ & $143 \pm 19$ & $138 \pm 19$ & 0.330 \\
\hline $\mathrm{CDBP}, \mathrm{mmHg}$ & $74.5 \pm 8.6$ & $77.3 \pm 10.2$ & 0.188 \\
\hline CMAP, mmHg & $97.1 \pm 10.9$ & $97.8 \pm 11.5$ & 0.791 \\
\hline $\mathrm{CPP}, \mathrm{mmHg}$ & $67.8 \pm 16.7$ & $61.4 \pm 16.5$ & 0.085 \\
\hline ACR & $>30 \mathrm{mg} / \mathrm{g}(n=43)$ & $\leq 30 \mathrm{mg} / \mathrm{g}(n=78)$ & \\
\hline $\mathrm{CSBP}, \mathrm{mmHg}$ & $144 \pm 19$ & $136 \pm 18$ & 0.034 \\
\hline $\mathrm{CDBP}, \mathrm{mmHg}$ & $76.2 \pm 10.0$ & $76.5 \pm 9.7$ & 0.877 \\
\hline CMAP, mmHg & $98.7 \pm 11.2$ & $96.6 \pm 11.0$ & 0.303 \\
\hline $\mathrm{CPP}, \mathrm{mmHg}$ & $67.8 \pm 18.5$ & $60.1 \pm 14.8$ & 0.015 \\
\hline baPWV & $>1,600 \mathrm{~cm} / \mathrm{sec}(n=57)$ & $\leq 1,600 \mathrm{~cm} / \mathrm{sec}(n=77)$ & \\
\hline CSBP, mmHg & $145 \pm 19$ & $135 \pm 18$ & 0.003 \\
\hline $\mathrm{CDBP}, \mathrm{mmHg}$ & $77.3 \pm 10.5$ & $76.3 \pm 9.6$ & 0.578 \\
\hline CMAP, mmHg & $99.9 \pm 11.9$ & $95.9 \pm 10.7$ & 0.043 \\
\hline $\mathrm{CPP}, \mathrm{mmHg}$ & $68.0 \pm 16.6$ & $58.8 \pm 15.7$ & 0.001 \\
\hline$A B I$ & $<0.9(n=9)$ & $\geq 0.9(n=125)$ & \\
\hline $\mathrm{CSBP}, \mathrm{mmHg}$ & $145 \pm 24$ & $139 \pm 19$ & 0.353 \\
\hline $\mathrm{CDBP}, \mathrm{mmHg}$ & $67.6 \pm 11.4$ & $77.4 \pm 9.6$ & 0.004 \\
\hline CMAP, $\mathrm{mmHg}$ & $93.6 \pm 14.6$ & $97.9 \pm 11.1$ & 0.277 \\
\hline
\end{tabular}


Table 4 Mean values of central blood pressure measurements according to the presence of TOD (Continued)

\begin{tabular}{|c|c|c|c|}
\hline Variable & TOD (+) & TOD (-) & P-value \\
\hline $\mathrm{CPP}, \mathrm{mmHg}$ & $77.8 \pm 17.3$ & $61.7 \pm 16.2$ & 0.005 \\
\hline
\end{tabular}

kidney and brain, and flow derived by CBP influences the local flow into these vital organs [13]. Therefore, CBP could be better correlated with cardiovascular prognosis and TOD than BrBP [9]. In the Strong Heart Study, CBP was more strongly associated with future cardiovascular events than BrBP in disease-free individuals [5]. Other studies have shown that CBP lowering may be responsible for $\mathrm{LVH}$ regression and the improvement in cardiovascular prognosis beyond BrBP lowering $[8,36]$. These findings support the hypothesis that CBPlowering drugs may be more effective than BrBPtargeting ones [8].

It is not well-known which CBP measurements are clinically relevant. A few studies have emphasized the importance of CPP, as it was associated with the risk of TOD and ASCVD. Jankowski et al. [37] showed that CPP and pulsatility of the central aorta were the most important factors related to CAD rather than BrBP, and Central Aortic Pressure and Clinical Outcomes (CAFÉ) study also revealed that CPP may be a main determinant of clinical outcomes [8]. Madhavan et al. [38] demonstrated that the wider pulse pressure (PP) was identified as a predictor of myocardial infarction. In line with these studies, our findings also showed that CPP was most important factor predicting TOD among CBP measurements.

Possible mechanisms explaining the association between CPP and TOD can be suggested. Elevation of PP is both a cause and a result of arterial damage and atherosclerosis. Degenerative changes in the aortic wall and arterial tree by aging increase stiffness of the aorta, and lead to an increase in PP [39]. With repeated exposure to increased CPP, the arteries are directly damaged and arteriosclerosis progresses [21]. Progressive aortic stiffness increases systolic BP and decreases diastolic BP, which makes CPP wider [40]. Therefore, CPP is an indicator of aortic stiffness. Patients with increased aortic stiffness share common cardiovascular risk factors of TOD, such as aging, high BP, hyperglycemia, and dyslipidemia [41]. In addition, increased systolic BP cause $\mathrm{LVH}$, and low diastolic BP is associated with decreased coronary blood flow [42].

Risk stratification and early aggressive management for high-risk patients is important for preventing future cardiovascular events and for reducing morbidity and mortality. The present study revealed that CBP, especially $\mathrm{CPP}$, is valuable in the prediction of TOD. Measurement of CBP using radial artery tonometry, which is noninvasive and well-validated, could be useful for the risk stratification of high-risk patients. This study could also be a hypothesis-generating trial for further investigations into the development of novel medications lowering CPP or using CPP as a monitoring tool.

Some limitations are present in this study. First, because cardiovascular outcomes, such as myocardial infarction or mortality, were not investigated, we could not conclude whether CPP was related to long-term prognoses of patients. However, as TOD is a well-known factor closely related to worse cardiovascular outcomes $[19,20]$, CPP might be a prognostic factor of future

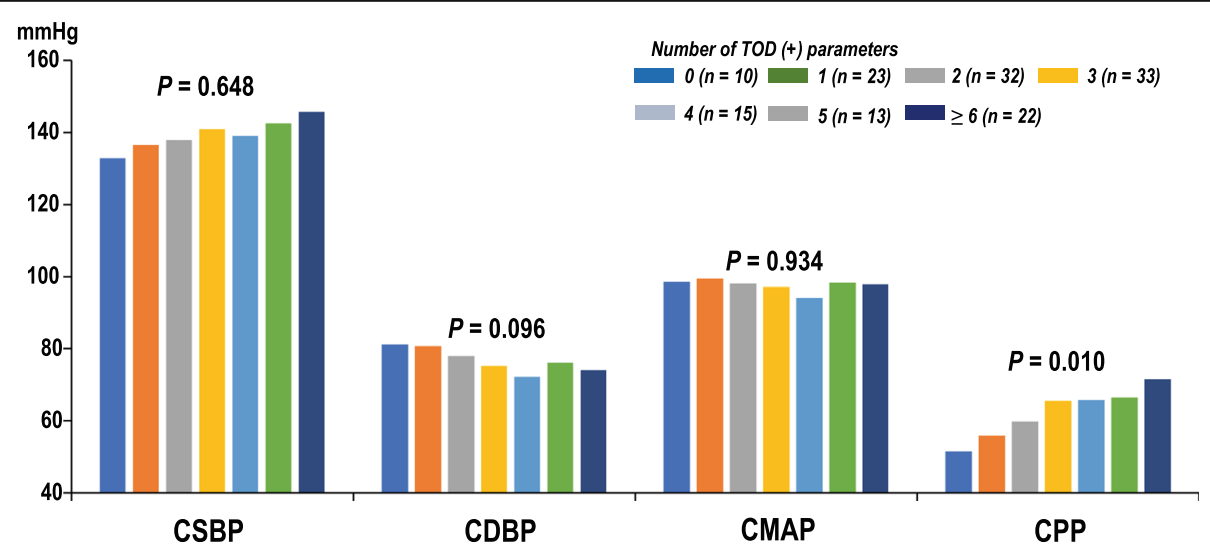

Fig. 2 Association between central blood pressure and the number of TOD parameters. CSBP, central systolic blood pressure; CDBP, central diastolic blood pressure; CMAP, central mean arterial pressure; CPP, central pulse pressure; TOD, target organ damage 
cardiovascular events. Longitudinal studies with a larger sample size are warranted. Secondly, due to the relatively small number of study patients, we were able to show only weak linear correlations between $\mathrm{CBP}$ and the parameters of TOD. There was also a possibility that associations between some other CBP measurements and TOD did not reach statistical significance. For similar reason, the superiority of $\mathrm{CBP}$ over BrBP could not be proved in this study, however, the purpose of our study is not to compare CBP and BrBP. Thirdly, the duration or risk factors of ASCVD could have had an effect on CBP measurements and TOD; however, our data did not provide information on this. Finally, as our data were collected from Korean patients at high coronary risk, it should be cautious in applying them to other ethnic groups of patients.

\section{Conclusions}

CPP had a stronger correlation with TOD than other CBP measurements in patients with ASCVD or multiple risk factors. Non-invasive measurement of CPP may be a useful tool for risk stratification of high-risk patients.

\section{Abbreviations \\ ABI: Ankle-brachial index; ACR: Albumin-creatinine ratio; ASCV $D$ : Atherosclerotic cardiovascular disease; baPW: Brachial-ankle pulse wave velocity; BP: Blood pressure; BrBP: Brachial blood pressure; BrDBP: Brachial diastolic blood pressure; BrMAP: Brachial mean arterial pressure; BrPP: Brachial pulse pressure; BrSBP: Brachial systolic blood pressure; CAD: Coronary artery disease; CBP: Central blood pressure; CDBP: Central diastolic blood pressure; CKD: Chronic kidney disease; CMAP: Central mean arterial pressure; CPP: Central pulse pressure; CSBP: Central systolic blood pressure; CVD: Cardiovascular disease; eGFR: Estimated glomerular filtration rate; LV: Left ventricular; LVH: Left ventricular hypertrophy; LVMI: Left ventricular mass index; MDRD: Modification of diet in renal disease; NT- proBNP: N-terminal pro-brain natriuretic peptide; PP: Pulse pressure; RWT: Relative wall thickness; TOD: Target organ damage}

\section{Acknowledgements}

Not applicable.

\begin{abstract}
Authors' contributions
$\mathrm{KHJ}$ and HLK conceived of this study, participated in its design and coordination, analyzing data, and writing a draft of this manuscript. WHL and JBS participated in obtaining written informed consents from patients, obtaining waveforms, and data analysis. SHK, JHZ, and MAK participated in data analysis, and helped to conduct the literature review and draft the manuscript. HLK is the principal investigator and contributed to the idea and design of this study, interpreted the data, undertook the data analysis, and contributed to subsequent drifts. All authors read and approved the final manuscript.
\end{abstract}

\section{Funding}

No funding was received for this study.

\section{Availability of data and materials}

The datasets used and/or analyzed during the current study are available from the corresponding author on reasonable request.

\section{Declarations}

\section{Ethics approval and consent to participate}

The study protocol was approved by the Institutional Review Board (IRB) of Boramae Medical Center (Seoul, Korea) (IRB number, 26-2017-55) and written informed consent was obtained from each study patient.

\section{Consent for publication}

Not applicable.

\section{Competing interests}

The authors declare that they have no competing interests.

\section{Author details}

${ }^{1}$ Cardiovascular center, Department of Internal Medicine, Seoul National University Bundang Hospital, Seongnam, Republic of Korea. ${ }^{2}$ Division of Cardiology, Department of Internal Medicine, SMG-SNU Boramae Medical Center, Seoul, Republic of Korea.

Received: 5 July 2021 Accepted: 9 September 2021

Published online: 01 December 2021

\section{References}

1. Lim SS, Vos T, Flaxman AD, Danaei G, Shibuya K, Adair-Rohani H, et al. A comparative risk assessment of burden of disease and injury attributable to 67 risk factors and risk factor clusters in 21 regions, 1990-2010: a systematic analysis for the Global Burden of Disease Study 2010. Lancet. 2012;380: 2224-60.

2. Lewington S, Clarke R, Qizilbash N, Peto R, Collins R, Prospective Studies Collaboration. Age-specific relevance of usual blood pressure to vascular mortality: a meta-analysis of individual data for one million adults in 61 prospective studies. Lancet. 2002;360:1903-13.

3. Williams B, Mancia G, Spiering W, Agabiti Rosei E, Azizi M, Burnier M, et al. 2018 ESC/ESH Guidelines for the management of arterial hypertension. Eur Heart J. 2018:39:3021-104.

4. Whelton PK, Carey RM, Aronow WS, Casey DE Jr, Collins KJ, Dennison Himmelfarb C, et al 2017 ACC/AHA/AAPA/ABC/ACPM/AGS/APhA/ASH/ ASPC/NMA/PCNA Guideline for the prevention, detection, evaluation, and management of high blood pressure in adults: a report of the American College of Cardiology/American Heart Association Task Force on Clinical Practice Guidelines. Circulation. 2018;138:e484-594.

5. Roman MJ, Devereux RB, Kizer JR, Lee ET, Galloway JM, Ali T, et al. Central pressure more strongly relates to vascular disease and outcome than does brachial pressure: the Strong Heart Study. Hypertension. 2007;50:197-203.

6. Safar ME, Blacher J, Pannier B, Guerin AP, Marchais SJ, Guyonvarc'h PM, et al. Central pulse pressure and mortality in end-stage renal disease. Hypertension. 2002;39:735-8.

7. Pini R, Cavallini MC, Palmieri V, Marchionni N, Di Bari M, Devereux RB, et al. Central but not brachial blood pressure predicts cardiovascular events in an unselected geriatric population: the ICARe Dicomano Study. J Am Coll Cardiol. 2008:51:2432-9.

8. Williams B, Lacy PS, Thom SM, Cruickshank K, Stanton A, Collier D, et al. Differential impact of blood pressure-lowering drugs on central aortic pressure and clinical outcomes: principal results of the Conduit Artery Function Evaluation (CAFE) study. Circulation. 2006;113:1213-25.

9. Kollias A, Lagou S, Zeniodi ME, Boubouchairopoulou N, Stergiou GS. Association of central versus brachial blood pressure with target-organ damage: systematic review and meta-analysis. Hypertension. 2016;67:18390.

10. Vlachopoulos C, Aznaouridis K, O'Rourke MF, Safar ME, Baou K, Stefanadis C. Prediction of cardiovascular events and all-cause mortality with central haemodynamics: a systematic review and meta-analysis. Eur Heart J. 2010; 31:1865-71.

11. Yamashita S, Dohi Y, Takase H, Sugiura T, Ohte N. Central blood pressure reflects left ventricular load, while brachial blood pressure reflects arterial damage. Blood Press. 2014;23:356-62.

12. Wohlfahrt P, Wichterle D, Seidlerová J, Filipovský J, Bruthans J, Adámková $V$, et al. Relation of central and brachial blood pressure to left ventricular hypertrophy. The Czech Post-MONICA Study. J Hum Hypertens. 2012;26:14-9. 
13. McEniery CM, Cockcroft JR, Roman MJ, Franklin SS, Wilkinson IB. Central blood pressure: current evidence and clinical importance. Eur Heart J. 2014; 35:1719-25.

14. Kroeker EJ, Wood EH. Comparison of simultaneously recorded central and peripheral arterial pressure pulses during rest, exercise and tilted position in man. Circ Res. 1955:3:623-32.

15. Pauca AL, O'Rourke MF, Kon ND. Prospective evaluation of a method for estimating ascending aortic pressure from the radial artery pressure waveform. Hypertension. 2001;38:932-7.

16. Ohte N, Saeki T, Miyabe H, Sakata S, Mukai S, Hayano J, et al. Relationship between blood pressure obtained from the upper arm with a cuff-type sphygmomanometer and central blood pressure measured with a cathetertipped micromanometer. Heart Vessels. 2007;22:410-5.

17. Kim HL, Seo JB, Chung WY, Kim SH, Kim MA, Zo JH. Association between invasively measured central aortic pressure and left ventricular diastolic function in patients undergoing coronary angiography. Am J Hypertens. 2015:28:393-400

18. Takazawa K, Kobayashi H, Shindo N, Tanaka N, Yamashina A. Relationship between radial and central arterial pulse wave and evaluation of central aortic pressure using the radial arterial pulse wave. Hypertens Res. 2007;30: 219-28.

19. Devereux RB, Alderman MH. Role of preclinical cardiovascular disease in the evolution from risk factor exposure to development of morbid events. Circulation. 1993;88:1444-55.

20. Messerli FH, Williams B, Ritz E. Essential hypertension. Lancet. 2007;370:591603.

21. Hayashi K, Ide K, Matsumoto T. Aortic walls in atherosclerotic rabbits: mechanical study. J Biomech Eng. 1994;116:284-93.

22. Masugata H, Senda S, Okuyama H, Murao K, Inukai M, Hosomi N, et al. Comparison of central blood pressure and cardio-ankle vascular index for association with cardiac function in treated hypertensive patients. Hypertens Res. 2009;32:1136-42.

23. Roman MJ, Okin PM, Kizer JR, Lee ET, Howard BV, Devereux RB. Relations of central and brachial blood pressure to left ventricular hypertrophy and geometry: the Strong Heart Study. J Hypertens. 2010;28:384-8.

24. Westerbacka J, Leinonen E, Salonen JT, Salonen R, Hiukka A, Yki-Järvinen H, et al. Increased augmentation of central blood pressure is associated with increases in carotid intima-media thickness in type 2 diabetic patients. Diabetologia. 2005;48:1654-62.

25. DeLoach SS, Appel LJ, Chen J, Joffe MM, Gadegbeku CA, Mohler ER 3rd, et al. Aortic pulse pressure is associated with carotid IMT in chronic kidney disease: report from Chronic Renal Insufficiency Cohort. Am J Hypertens. 2009;22:1235-41.

26. Oliveras A, García-Ortiz L, Segura J, Banegas JR, Martell-Claros N, Vigil L, et al. Association between urinary albumin excretion and both central and peripheral blood pressure in subjects with insulin resistance. J Hypertens. 2013;31:103-8

27. Bots ML, Dijk JM, Oren A, Grobbee DE. Carotid intima-media thickness, arterial stiffness and risk of cardiovascular disease: current evidence. J Hypertens. 2002;20:2317-25.

28. Levey AS, Bosch JP, Lewis JB, Greene T, Rogers N, Roth D. A more accurate method to estimate glomerular filtration rate from serum creatinine: a new prediction equation. Modification of Diet in Renal Disease Study Group. Ann Intern Med. 1999;130:461-70.

29. Takase H, Dohi Y, Kimura G. Distribution of central blood pressure values estimated by Omron HEM-9000AI in the Japanese general population. Hypertens Res. 2013;36:50-7.

30. Lang RM, Badano LP, Mor-Avi V, Afilalo J, Armstrong A, Ernande L, et al. Recommendations for cardiac chamber quantification by echocardiography in adults: an update from the American Society of Echocardiography and the European Association of Cardiovascular Imaging. J Am Soc Echocardiogr. 2015;28:1-39.e14

31. Nagueh SF, Smiseth OA, Appleton CP, Byrd BF 3rd, Dokainish H, Edvardsen $T$, et al. Recommendations for the evaluation of left ventricular diastolic function by echocardiography: an update from the American Society of Echocardiography and the European Association of Cardiovascular Imaging. Eur Heart J Cardiovasc Imaging. 2016;17:1321-60.

32. Kwon JE, Mintz GS, Kim SW, Oh MS, Min YJ, Kim HK, et al. Relationship between coronary artery plaque composition by virtual histology intravascular ultrasound analysis and brachial-ankle pulse wave velocity in patients with coronary artery disease. Coron Artery Dis. 2011;22:565-9.
33. Ojima S, Kubozono T, Kawasoe S, Kawabata T, Miyata M, Miyahara H, et al. Association of risk factors for atherosclerosis, including high-sensitivity Creactive protein, with carotid intima-media thickness, plaque score, and pulse wave velocity in a male population. Hypertens Res. 2020;43:422-30.

34. Waddell TK, Dart AM, Medley TL, Cameron JD, Kingwell BA. Carotid pressure is a better predictor of coronary artery disease severity than brachial pressure. Hypertension. 2001;38:927-31.

35. Wang KL, Cheng HM, Chuang SY, Spurgeon HA, Ting CT, Lakatta EG, et al. Central or peripheral systolic or pulse pressure: which best relates to target organs and future mortality? J Hypertens. 2009;27:461-7.

36. Asmar RG, London GM, O'Rourke ME, Safar ME, REASON Project Coordinators and Investigators. Improvement in blood pressure, arterial stiffness and wave reflections with a very-low-dose perindopril/indapamide combination in hypertensive patient: a comparison with atenolol. Hypertension. 2001;38:922-6.

37. Jankowski P, Kawecka-Jaszcz K, Czarnecka D, Brzozowska-Kiszka M, Styczkiewicz K, Loster M, et al. Pulsatile but not steady component of blood pressure predicts cardiovascular events in coronary patients. Hypertension. 2008:51:848-55.

38. Madhavan S, Ooi WL, Cohen H, Alderman MH. Relation of pulse pressure and blood pressure reduction to the incidence of myocardial infarction. Hypertension. 1994;23:395-401.

39. Avolio A, Jones D, Tafazzoli-Shadpour M. Quantification of alterations in structure and function of elastin in the arterial media. Hypertension. 1998; 32:170-5.

40. Franklin SS, Gustin W 4th, Wong ND, Larson MG, Weber MA, Kannel WB, et al. Hemodynamic patterns of age-related changes in blood pressure. The Framingham Heart Study Circulation. 1997;96:308-15.

41. Cavalcante JL, Lima JA, Redheuil A, Al-Mallah MH. Aortic stiffness: current understanding and future directions. J Am Coll Cardiol. 2011:57:1511-22.

42. Kim HL, Kim SH. Pulse wave velocity in atherosclerosis. Front Cardiovasc Med. 2019;6:41.

\section{Publisher's Note}

Springer Nature remains neutral with regard to jurisdictional claims in published maps and institutional affiliations.

Ready to submit your research? Choose BMC and benefit from:

- fast, convenient online submission

- thorough peer review by experienced researchers in your field

- rapid publication on acceptance

- support for research data, including large and complex data types

- gold Open Access which fosters wider collaboration and increased citations

- maximum visibility for your research: over $100 \mathrm{M}$ website views per year

At BMC, research is always in progress.

Learn more biomedcentral.com/submission 